\title{
Correction: Whole-genome sequencing of chronic lymphocytic leukaemia reveals distinct differences in the mutational landscape between IgHV ${ }^{\text {mut }}$ and IgHV $\mathrm{Inmut}^{\text {subgroups }}$
}

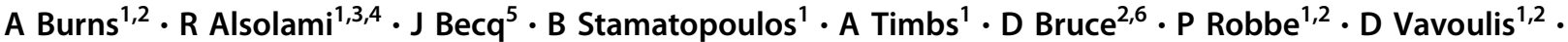

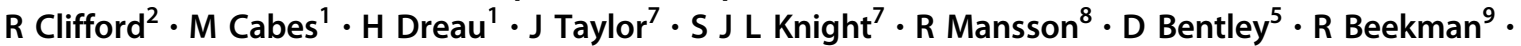 \\ J I Martín-Subero ${ }^{9} \cdot$ E Campo $^{10} \cdot$ R S Houlston ${ }^{11} \cdot \mathrm{K} \mathrm{E} \mathrm{Ridout}^{1,2} \cdot$ A Schuh $^{1,2,6}$
}

Published online: 17 July 2019

(c) The Author(s), under exclusive licence to Springer Nature Limited 2019. This article is published with open access

\section{Correction to: Leukemia}

https://doi.org/10.1038/leu.2017.177

Published online 6 June 2017

This article was originally published under CC BY-NC-ND 4.0, but has now been made available under a CC BY 4.0 license. The PDF and HTML versions of the paper have been modified accordingly.

These authors contributed equally: A Burns, R Alsolami, B Stamatopoulos, R Clifford

These senior authors contributed equally: KE Ridout, A Schuh

The original article can be found online at https://doi.org/10.1038/leu. 2017.177.

\section{A Schuh}

anna.schuh@oncology.ox.ac.uk

1 Department of Molecular Haematology, Oxford Molecular Diagnostics Centre, John Radcliffe Hospital, Oxford, UK

2 Department of Oncology, University of Oxford, Oxford, UK

3 Nuffield Department of Clinical Laboratory Sciences, University of Oxford, Oxford, UK

4 King Abdulaziz University, Faculty of Applied Medical Sciences, Jeddah, Saudi Arabia

5 Illumina Cambridge Ltd, Saffron Walden, UK

6 Department of Haematology, Oxford University Hospitals NHS Trust, Oxford, UK
Open Access This article is licensed under a Creative Commons Attribution 4.0 International License, which permits use, sharing, adaptation, distribution and reproduction in any medium or format, as long as you give appropriate credit to the original author(s) and the source, provide a link to the Creative Commons license, and indicate if changes were made. The images or other third party material in this article are included in the article's Creative Commons license, unless indicated otherwise in a credit line to the material. If material is not included in the article's Creative Commons license and your intended use is not permitted by statutory regulation or exceeds the permitted use, you will need to obtain permission directly from the copyright holder. To view a copy of this license, visit http://creativecommons. org/licenses/by/4.0/.

7 Wellcome Trust Centre for Human Genetics, University of Oxford, Oxford, UK

8 Center for Hematology and Regenerative Medicine Huddinge, Karolinska Institute, Stockholm, Sweden

9 Biomedical Epigenomics Group, Institut d'Investigacions Biomédiques August Pi i Sunyer (IDIBAPS), University of Barcelona, Barcelona, Spain

10 Hematopathology Unit, Hospital Clinic, Institut d'Investigacions Biomèdiques August Pi i Sunyer (IDIBAPS), University of Barcelona, Barcelona, Spain

11 Division of Molecular Pathology, The Institute of Cancer Research, London, UK 